\section{AUSCULTAR ROSA E OUVIR HOMERO}

\author{
Tereza Virgínia Ribeiro Barbosa*
}

Recebido em: 18/03/2019

Aprovado em: 15/04/2019

RESUMO: Neste artigo propomos leituras do Grande Sertão: veredas, de João Guimarães Rosa, e dos poemas homéricos, mais especificamente a Ilíada, com performances dialetais diferentes. Nosso intuito será comprovar (a partir de rotacismos, apócopes, aféreses, síncopes etc.) a amplificação de sentido que advém dessas alterações fonéticas no contexto das obras em foco como um todo. Visamos ao estudo dos metaplasmos como mecanismo que flexibiliza o texto poético e que lhe faculta a dinamicidade, a espacialidade cultural e a fugacidade do oral. Com o recurso de potencializar metaplasmos, o texto ganha novos sentidos no tempo e no espaço. Recuperam-se as estratégias de oralidade do português brasileiro e, através delas, projetam-se aquelas da chamada 'língua morta' de Homero.

PALAVRAS-CHAVE: Metaplasmos; Guimarães Rosa; Homero.

AUSCULTATING ROSA AND HEARING HOMER

\begin{abstract}
In this paper, we propose readings of the Grande Sertão: veredas of João Guimarães Rosa and of the Homeric Poems, more specifically the Iliad, with different dialectal performances. Our intention is to prove (from rhotacisms, apocopes, apheresis, syncopes, etc.) the amplification of meaning that comes from these phonetic changes in the context of the works in focus as a whole. We aim at the study of metaplasms as a mechanism that ventilates the poetic text and which gives it the dynamicity, the cultural spatiality and the fugacity of the oral. With the ability to potentiate metaplasms, the text gains new meanings in time and space. The strategies of orality of Brazilian Portuguese are recovered and, through them, those of the so-called 'dead language' of Homer are projected.
\end{abstract}

KEYWORDS: Metaplasms; Guimarães Rosa; Homer.

\author{
* Professora \\ Titular de Língua \\ e Literatura Grega, \\ Universidade Federal \\ de Minas Gerais. \\ tereza.virginia.ribeiro. \\ barbosa@gmail.com
}

(I) 


\section{Poesia, OFERTA DE OCASIÃo}

$\mathrm{P}$ or que comparar os poemas de Homero com obras escritas em uma língua que ele nunca conheceu e com um autor que ele nunca leu? E mais, compará-lo com um literal escrevinhador de caderninhos com lápis e borracha em mãos, de tempo e cultura tão distantes e diferentes; por que associá-lo a um tal João Rosa da família dos Guimarães?

A primeira resposta que temos para oferecer é, em linhas gerais, o fato de estarmos buscando, com esta comparação, um universal poético - e linguístico - que alargue a nossa compreensão de ambos e que revele características comuns de suas grandes composições.

Nosso estudo compreenderá, portanto, a literatura como um corpo constituído de textos, de teorias e histórias acerca desses textos, de sons encarnados, de estudos de cultura e língua e de falantes (referimo-nos, em relação a esse último campo, à sociolinguística, evidentemente). Investigamos, talvez, uma poética comum implicita ${ }^{1}$ entre dois monumentos, a saber, Homero e João Guimarães Rosa.

Muito já se (ou)viu da influência de Homero no Grande Sertão: veredas, de Guimarães Rosa, e em numerosos contos da obra do mineiro. Tais estudos foram desenvolvidos por classicistas que focalizaram o suporte cultural e material da palavra escrita, o substrato dos mitos e as muitas estratégias narrativas empregadas nos textos antigos e recriadas ou resgatadas pelo escritor e médico mineiro. Nesse tipo de abordagem quase sempre predomina a contraposição de escritura contra escritura, partindo-se, também, de uma tímida assunção da impossibilidade de recuperar, com exatidão, seja a oralidade e a situação da cantoria homérica seja a discursividade sonora do Riobal/rdo, o rio cantador de Cordisburgo, em sua conversa com "o senhor" seu interlocutor.

Felizmente, não são tão pujantes os obstáculos dessa natureza no que concerne à fala do sertanejo das Minas Gerais, que é de certo modo mais próxima de nós e recuperável - ainda que precariamente - em gravações antigas de cinquenta ou sessenta anos atrás. Contudo, se é de fato inegável que algumas das mais sutis interações poéticas são originadas da percepção destes textos lidos em voz alta (aferíveis, portanto, pela ausculta das gravações antigas no caso de Rosa), é também incontestável que a leitura oral destes textos nunca é igual, por contingência natural e fenomênica (variam a dicção individual e a origem regional do performer, a dicção vigente na diacronia da língua para os fonemas utilizados nas palavras proferidas, o ritmo, o tom, o timbre, a textura da voz, sua modulação, altura, intenção...' ${ }^{2}$.

Performances se dão no eixo irrecuperável do tempo da produção de um desempenho particular; seu valor advém do conhecimento de que são únicas. A cada leitura de viva voz, surge uma interpretação inédita do pensamento expresso nos símbolos escritos; a cada

\footnotetext{
${ }^{1}$ Meiner, 1996.

2 Para um vislumbre da potência da oralidade sugerimos o estudo de Raymond Murray Schafer intitulado "Quando as palavras cantam", um capítulo do livro O ouvido pensante (Schafer, 1991, p. 207-67).
} 
vocalização, uma inusitada tradução da escritura muda (em sons articulados e ritmados que nunca haverão de ser repetidos por outrem). ${ }^{3}$

Contudo, no caso desses dois portentos, Homero e Rosa, não bastam as performances artísticas apoiadas na novidade da efemeridade e preocupadas em suscitar a perplexidade de um auditório frente a uma descoberta inaugural. Não. As performances de Homero e Rosa (seja por atos de fala, seja por leituras silenciosas e solitárias) carregam memórias "nacionais" de culturas (com seus mitos, com seu valor de representação de um povo, com sua história textual de um sistema literário universal) e, por isso, firmam, no efêmero, o imutável. As sincronizações do novo com o antigo, nesses casos, são atualizações renovadas ad aeternum. Ler Homero e Rosa, praticar Homero e Rosa, é fazê-los acontecer.

Ancestralidade e novidade em parceria é o que propõe, igualmente, Gregory Nagy em "Genre and occasion” (1994). Nagy, preocupado com a definição dos gêneros literários, desenvolve sua argumentação na direção de associá-los ao contexto de uma situação ritualística, de um evento público que se realiza através de um ato de fala ${ }^{4}$ (ação verbal que altera a realidade social, moral e religiosa) capaz de criar uma realidade paralela. Afirma ele que

The genre, the set of rules that generate a given speech act, can equate itself with the occasion, the context of this speech act. To this extent, the occasion is the genre. For example, a song of lament can equate itself with the process of grieving for the dead. Moreover, if the occasion is destabilized or even lost, the genre can compensate for it, even re-create it. (Nagy, 1994, p. 13)

O gênero, o conjunto de regras que geram um determinado ato de fala, pode se igualar à ocasião, ao contexto desse ato de fala. Nesse sentido, a ocasião é o gênero. Por exemplo, uma canção de lamento pode se igualar ao processo de luto pelos mortos. Além disso, se a ocasião é desestabilizada ou até mesmo perdida, o gênero pode compensá-la, inclusive recriá-la.

Assim, resumindo, pode-se dizer que a ocasião faz o gênero; faz a poesia o ato de criação. E, no caso, qual é a situação de Homero e de Rosa senão a de dois contadores de histórias? Suas performances se confundem com as suas $\mu \mu \eta \dot{\sigma \varepsilon ı \varsigma, ~ q u e, ~ p o r ~ s u a ~ v e z, ~ s e ~}$ realizam como acontecimento convival onde "la presencia aurática corporal" é "productora de poíesis" (Dubatti, 2016, p. 4). ${ }^{5}$

\footnotetext{
${ }^{3}$ Iniciamos o parágrafo mencionando gravações antigas que recuperam sutilezas de pronúncia que nos levam a possíveis oralizações perdidas, acervo precioso que, todavia, não substitui a performance oral. Gravações são uma espécie de escritura imutável mais congelada que o texto escrito, que, frente a elas, é bem mais aberto a novas e inusitadas interpretações através dos tempos e das culturas; por fixar um registro singular específico, as gravações são, ao fim e ao cabo, um empobrecimento do escrito. ${ }^{4}$ Nagy recupera a teoria do filósofo da linguagem John Langshaw Austin (todo dizer é um fazer).

${ }^{5}$ Para Jorge Dubatti (2016, p. 3), o acontecimento convival limiar é o teatro, espaço simbólico onde se estabelece “... un uso singular de la organización de la mirada, que exige: reunión, poiesis corporal y
} 


\section{Nominata EM PLENIFICAÇÃO: VOLATILIDAdE E MUTABILIDADE}

Outra realidade já demasiadamente conhecida é que tanto os poemas homéricos quanto a obra do viator do rio Paraopeba ${ }^{6}$ - circunscrevemo-nos aqui à Ilíada e ao Grande Sertão: veredas - confirmam uma linguagem multiforme e compósita, representativa de um amplo território linguístico, em arquivos estruturados para serem lidos e ouvidos sob um único registro escrito e que só se realizam plenamente quando a voz está em movimento. Jogo ousado e pretendido implicitamente na concepção da fórmula homérica ě $\pi \varepsilon \alpha \pi \tau \varepsilon \rho o ́ \varepsilon v \tau \alpha$, que Guimarães Rosa traduziu habilmente em $A v e$, palavra, compilação de textos "quase" teóricos sobre a criação literária. Neles, a palavra volátil "vale pela sua forma, pelo seu som, pela sua significação, por sua novidade ou mesmo por sua ancianidade...” (Oliveira, 2008, p. 140).

De modo semelhante e enquanto literatura de fundação de uma "helenidade", a Ilíada congrega a variedade de falares de muitas regiões da Grécia com os seus múltiplos dialetos reunidos em um texto coeso. Visto por este ângulo, seu modo de estruturação auxilia a reconfigurar o Grande Sertão: veredas para abordá-lo como literatura que quebra preconceitos linguísticos, apresentando, em sua sofisticada e cuidada tessitura, o alto grau de diversidade e de variabilidade da língua portuguesa no Brasil, ${ }^{8}$ incluindo até mesmo a incorporação de

expectación. La Filosofía del Teatro define ese uso como un acontecimiento en el que artistas, técnicos y espectadores se reúnen de cuerpo presente (el convivio) para expectar (recordemos que el término teatro, en griego, théatron, podría traducirse 'mirador', 'observatorio') la aparición y configuración de uma construcción de naturaleza metafórica, mundo paralelo al mundo, con sus propias reglas, en el cuerpo de los actores (Aristóteles, en su Poética, llama a esa construcción poíesis y de ese término proviene la palabra poesía)." Aplicamos a expressão em sentido lato para o ato performático de contar/narrar histórias, que seria o que Dubatti chama de teatro-matriz: "todos los acontecimientos en los que se reconoce la presencia conjunta y combinada de convivio, poesía corporal y expectación. (...) Invocamos um doble movimiento que persigue un equilíbrio de diacronía/sincronia/anacronía: del origen etimológico ancestral hacia el presente, de la contemporaneidad hacia el pretérito con una nueva carga semántica. Teatro-matriz, en tanto genérico, vale para pensar una estrutura común (y a la vez diversa) presente en el aedo de la Antigua Grecia, en el drama litúrgico medieval, el teatro de boulevard y el teatro realista, la performance y el happening." (Dubatti, 2016, p. 4).

${ }^{6} \mathrm{O}$ Rio Paraopeba foi um reduto de beleza que hoje, lamentavelmente, foi severamente prejudicado pelo rompimento da barragem Mina Córrego do Feijão, que foi administrada, inescrupulosamente, por indústrias criminosas e por governos corruptos com décadas de exercício em Minas Gerais.

${ }^{7}$ A expressão - que é título de uma obra póstuma de Guimarães Rosa - pode ser lida de muitas formas: "primeiro, uma saudação de origem latina, uma interjeição que se dirige à palavra (...). Ela nos envia, além disso, à preocupação do autor com o fazer literário, com sua poética" (Oliveira, 2008, p. 139-40). Nós aqui acrescentamos outra a qual julgamos estar referendada por frase poética do próprio Guimarães Rosa (São Marcos, 2009, v. 1, p. 177): “as palavras têm canto e plumagem”; assim, para nós, ave é substantivo comum seguido do aposto palavra, e, deste modo, é uma tradução de ér $\varepsilon \alpha$

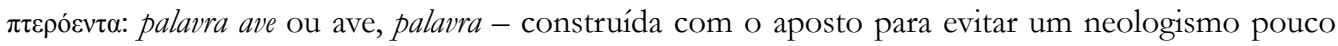
sonoro e indesejado "palave".

${ }^{8}$ Neste aspecto, temos como referência as obras de Bolle (2004); Bagno (2002, 2012); Montanari, Rengakos, Tsagalis (2012); Miller (2014). 
estrangeirismos, registrados a partir do ouvido, e trabalhados de forma, até então, inédita e requintada. ${ }^{9}$

Todavia, entre estes dois autores, admitindo, de maneira bem flexível, Homero como um autor, há um movimento de recepção inverso: um é regularmente aceito como literatura oral adéspota, fruto de uma tradição praticada, sabe-se lá por quanto tempo, sem a convenção da escrita e fixada a partir de um patrimônio oral circulante depois de aproximadamente dois séculos de criação; ${ }^{10}$ já a obra do outro, embora tenha data, local e mão autoral bem definidos, é arte que se almeja - ou que se simula - como prosa em evolução. Com efeito, prova em favor dessa percepção é a existência, já por mais de 20 anos, do Projeto Miguilim, empreendimento que capacita adolescentes e jovens cordisburguenses a verbalizar, ipsis litteris, contos, poemas e trechos da obra rosiana para públicos diversos.

Por meio desse raciocínio, se o texto grego passou, hipoteticamente, do oral para o escrito; o brasileiro (ao contrário e a julgar por sinalizações do autor em cartas, entrevistas e depoimentos) procurou resguardar a dimensão sonora, em voo pleno da narrativa pseudoimprovisada. Por consequência, constata-se que ele, ao ser oralizado, quer na solidão de gabinetes, por indivíduos, quer na performance propriamente dita, é mais bem entendido do que quando lido silenciosamente. Isso deve ser valorado e observado, pois Guimarães Rosa não é alheio às transformações às quais uma palavra se submete em sua produção verbalizada. Observemos um exemplo de suposta indecisão na pronúncia de um nome estrangeiro, motivação para evidenciar o potencial poético dessa exploração:

Ah, eh e não, alto-lá comigo, que assim falseio, o mesmo é. Pois ia me esquecendo: o Vupes! Não digo o que digo, se o do Vupes não orço - que teve, tãomente. Esse um era estranja, alemão, o senhor sabe: clareado, constituído forte, com os olhos azuis, esporte de alto, leandrado, rosalgar - indivíduo, mesmo. (...) "E como é mesmo que o senhor frasêia? Wusp? É. Seo Emílio Wuspes... Wupsis... Vupses. Pois esse Vupes apareceu lá, logo vai me reconheceu, como me conhecia, do Curralinho." (Rosa, GSV, 2009, p. 47-48)

\footnotetext{
${ }^{9}$ Sobre orientalismos no Grande Sertão: veredas, ver notícias de um estudo de William Myron Davis, (originalmente publicado na revista Romance Philology, n. 29, p. 409-34, 1976 e intitulado "Japanese Elements in 'Grande Sertão: veredas"') em Carvalho, 1976, p. 10. De nossa parte, citamos um trecho para melhor explicar a incorporação de estrangeirismos: - “... Uê, vim guerrear, de peito aberto, com estrondos. Não vim socolor de disfarces, com escondidos e logro. Perdi, por um desguardo. Não por má chefia minha! (Rosa, GSV, 2009, p. 182; grifos nossos). O termo socoloré dicionarizado, mas foi formado por uma "junção indevida", escritura tomada a partir da oralização do francês: sob cor de/ sous coleur de. ${ }^{10}$ Apesar de ter sido duramente criticada, a teorização de Parry e Lord - de que o básico da composição homérica seriam as fórmulas, $\mathrm{o}$ arcaísmo, as formações artificiais e os elementos estrangeiros à línguabase - sua hipótese fundamental é lógica. Parry postulou que a fórmula-verso perdera sua força semântica, guardando apenas uma função formal, que ela era usada por conveniência de composição, sem possuir qualquer significado particular. Seus sucessores comprovaram a presença inegável das fórmulas e acrescentaram análises comprobatórias da qualidade de uso das fórmulas na estruturação dos poemas. Cf. Reece, 2009.
} 
O parágrafo citado se inicia com uma estranha frase ( $A$ h, eh e não) seguida de uma advertência (assim falseio). ${ }^{11}$ Para a frase, observe-se que, se a lemos de uma determinada maneira, pronunciaremos (sem obviedade, pois o autor falseia o dito) o nome do generalmor dos aqueus na Ilíada: agá 'eh ê não [Agamenão]. Por que evocar o chefe dos chefes para descrever o Emílio Vupes/Wusp/Wuspes/Wupsis/Vupses? Importante lembrar que a origem latina do prenome citado é a mesma de "êmulo" e significa "rival".

Reiteramos: o escritor, avisando que falseia, fala de algo que, simultaneamente, é e não é a mesma coisa; solenemente ele declara que vai misturar as regras e levar o leitor/ ouvinte por pistas erradas. Se 'Vupes, Wusp...' é Agamenão, entendemos o porquê de ele ser 'leandrado', afinal, a imagem deste animal é uma das utilizadas para qualificar os heróis homéricos e, dentre eles, Agamenão (Ilíada, 10, v. 21-24; 11, v. 113, v. 129, v. 173). Contudo, como a frase em foco ( $A$ h, eh e não) sugere, Vulpes... é e não é Agamenão.

O motivo é fonético: o agá é e não é, pois a letra 'h' é muda em português, é figura sem som, é letra morta (que vive da escrita); o motivo é literário também, reescreve-se o antigo. Brincadeirinhas de sertanejo, pura mineiridade, escondição e ex-condição; forma de abrir horizontes, belos horizontes. O recurso está presente ainda na expressão esporte de alto [sport, ex-porte de alto, de porte (altivo), deportado, exportado] e no neologismo rosalgar $[$ rosa $=$ cor, autor e flor $=$ Guimarães Rosa (filho de Sêo Florduardo Rosa Pinto) + 'algar' = 'caverna, concavidade, gruta, mina, Minas' ou 'barranco resultante de enchentes ou enxurradas' ou 'abismo, ribanceira, despenhadeiro']. A riqueza do pequeno parágrafo - ao ser apreciado como palavra cantada e jogo literário - é inquestionável.

Em Homero, as formas que apresentam alternâncias, segundo Chantraine (1948, p. 95-112), são explicadas, via de regra, como uma tendência à acomodação métrica. É o caso,

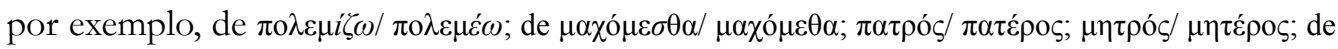

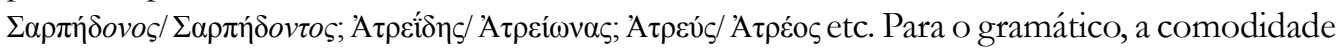
métrica exerceu influência sensível na estrutura das palavras dos poemas (Chantraine, 1948, p. 96). Entretanto, o mesmo pesquisador aponta no estudo da métrica homérica uma história complicada com contradições e confusões notáveis (Chantraine, 1948, p. 106, 96 e 98) e admite que "[1]a tradition manuscrite note les quantités par des procédés arbitraires." [A tradição manuscrita marca as quantidades por métodos arbitrários] (1948, p. 99). De fato, "dans la déclinaison même les aèdes scandent au datif singulier A $\chi \chi \imath \lambda \tilde{\eta} \check{\imath}$ en B 220, mais A A $\chi 1 \lambda \lambda \tilde{\eta} \bar{\imath}$ en $\Omega 119$, etc." [dentro de uma mesma declinação, os aedos escandem, no dativo singular A $\chi \imath \lambda \tilde{\eta} \tilde{\imath}$, em B 220, e, mais adiante, A $\chi \imath \lambda \lambda \tilde{\eta} \bar{i}$, em $\Omega$ 119, etc.] (Chantraine, 1948, p. 105).

Em estudo mais atualizado Ruth Scodel (2002, p. 99-116) indica que:

In recent years, scholars have paid considerable attention to Homeric semata. Gregory Nagy has examined the relationship between sêma and noesis in archaic hexameter poetry, seeing a parallelism between the intelligence required to encode and to decode signs. Andrew Ford discusses the grave marker as a foil for poetry; like epic song it can

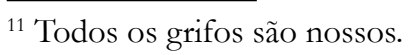


preserve fame, but it is liable to be destroyed, or moved, or to lose its meaning. Thus, for Ford, the sêma helps us see how Homer does not treat his song as a fixed monument. (Scodel, p. 99)

Nos últimos anos, estudiosos dedicaram considerável atenção aos semata homéricos. Gregory Nagy examinou a relação entre sêma e noesis na poesia hexamétrica arcaica, estabelecendo um paralelismo entre a inteligência exigida para codificar e decodificar sinais. Andrew Ford examina os marcos funerários como páginas de poesia; como uma canção épica que pode preservar a fama, mas que está sujeita a ser destruída, movida, ou a perder seu significado. Assim, para Ford, o sêma nos ajuda a ver como Homero não trata seu canto como um monumento fixo.

Quebrar o paradigma de imutabilidade absoluta do texto pode abrir novos horizontes, assim como conectar a recepção de um autor mais próximo com a de outro bem remoto. Para nós, um espelha o outro e, nessa relação, iluminam-se aspectos que se manteriam na sombra sem o auxílio da contraposição. Conjugá-los é se colocar em via de mão dupla. Quanto a Guimarães Rosa, ele próprio desvela um de seus procedimentos poéticos em carta a Curt Meyer-Clason, comentando a tradução de Bizzarri:

"Adino: Ai, Sé, op!" [é a tradução de Bizzarri]. No original [do Grande Sertão em português]: Adino: Aí, Zé, opa!” (...). AQUI, havia uma brincadeira. Leia, de trás para diante, e veja: a poesia. A POESIA." (Meyer-Clason, 2003, p. 207-8)

À recomendação de Rosa, "Leia de trás pra diante...", vamos acrescentar que Adino pode ser lido como anagrama de Adonai, o Senhor Deus dos Judeus, e é epônimo do rei bíblico Davi, poeta e cantador por excelência do povo hebreu. Portanto, o que temos com a frase senão "Deus é - de trás para frente - Poesia"?

Entendemos, portanto, que o estudo comparativo dessas duas estratégias de composição e criação poética pode reverter e 'reperspectivar' ambas, questionando algumas fortes tendências de estudo sobre elas, a saber: a defesa de uma oralidade inicial pura dos poemas homéricos e a abordagem dos textos rosianos tão somente pela escrita, sem sua associação com o exercício da produção oral. Trocando em miúdos, as duas obras estão estruturadas na transformação e não na fixação. Hipotetizando-as a partir do movimento da expressão oral, criamos um paralelismo quiásmico e teórico; cremos que o instrumento pode auxiliar no entendimento e na flexibilização interpretativa de vários contextos literários, para além de meneios gregos e mineiros. Neste sentido, vamos percorrer, recuperar e elencar paradigmas de potência oral e aplicá-los como exercício nos poemas homéricos e em Grande Sertão: veredas. Nosso percurso propõe o seguinte quiasma: 


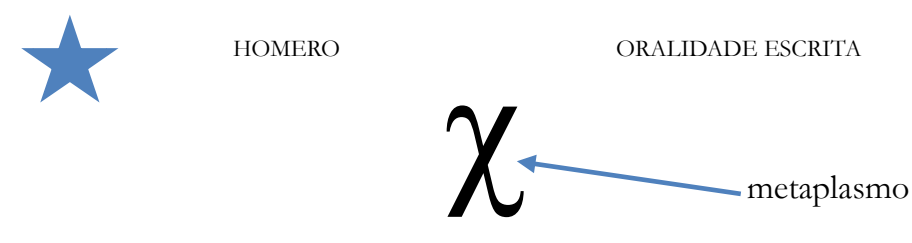

ROSA

ESCRITURA FALADA

\section{Metaplasmando}

Rosa ilumina Homero, Homero fundamenta Rosa; auscultar Rosa é ouvir e entender Homero. Pois bem, como poderíamos nos aproximar desses textos e vislumbrar as alterações inerentes à execução da fala no fluxo contínuo de suas performances? Acreditamos que a base que os sustenta é uma concepção comum de poesia em produção contínua, estado de constituição, pela palavra permanentemente emitida, de uma nação; dessa maneira, todos os falares de uma língua são, no plano estético, iguais para a produção de uma obra de arte.

Por isso, estamos buscando um repertório brasileiro de ع̌ $\pi \varepsilon \alpha \pi \tau \varepsilon \rho o ́ \varepsilon v \tau \alpha$, palavras voláteis e mutantes, o qual sugere, na inconstância da expressão oral de grupos variados, a variância e a imprevisibilidade de sentidos associáveis a partir do fluxo ininterrupto da língua. Nosso foco, a princípio, será a potência 'aural'12 dos textos a partir da observação e hipotetização de metaplasmos.

Seguimos as pegadas de Quintiliano (Institutio Oratoria, 1, 813-14), teórico para quem o mestre de literatura deve, principalmente, prestar atenção aos detalhes: tanto nas partes do discurso quanto nas características inerentes aos pés métricos. O orador (ou, se quiserem, o retórico) destaca os barbarismos, as palavras usadas de maneira imprópria, as utilizadas contra as leis da gramática; faz isso não para censurar os poetas, pois a eles é permitida tal licença, ou seja, a liberdade dos metaplasmos e das figuras de linguagem e de pensamento. Seu objetivo será, antes, familiarizar o aluno com os artifícios do estilo do poeta.

Propomos leituras com performances dialetais diferentes no intuito de comprovar (a partir de rotacismos, apócopes, aféreses, síncopes etc.) a amplificação de sentido que essas alterações fonéticas podem provocar no contexto da obra como um todo. A engenhosidade rosiana - que abona falares diferentes - desfaz preconceitos e elimina os tais 'erros de pronúncia' de falantes 'sertanejos ignorantes e sem recurso'. Incorporando-os às possibilidades poéticas do português brasileiro e à de Homero, referenda-se Rosa, recorrendo a um "pai fundador" do texto variegado que transita para a música e o teatro. Investiguemos alguns fenômenos linguísticos comuns que resgatam a fala do sertanejo-caipira-catrumano e que fazem dela ponte de erudição e sofisticação. Entendemos que, na sua proposta, o cordisburguense visou à valorização dos vários dialetos brasileiros e teceu uma obra como a de Homero, compósita e expressiva em sua enunciação à viva voz.

$\overline{12}$ Terminologia de Marília Librandi (2014). 


\section{Os GANHOS DOS METAPLASMOS}

$\mathrm{O}$ estudo dos metaplasmos como mecanismo que flexibiliza o texto poético (enrijecido pela escrita que o faz estático e linear) faculta a dinamicidade, a espacialidade cultural e a fugacidade do oral. A situação real da performance programada, encoberta pela prisão das palavras grafadas, dá indícios de revigorar-se; transformamos a análise de um texto transcrito ou transliterado numa exploração literário-cultural e espaço-temporal (pensamos em dialetos e falares regionais).

O sentido do texto passa a ser construído ao longo de uma possibilidade de enunciação no tempo e no espaço: recuperam-se as estratégias de oralidade do português brasileiro e, através delas, projetam-se aquelas da chamada 'língua morta' de Homero; os procedimentos recorrentes da poética de Guimarães Rosa são identificados com mais naturalidade e assim mais facilmente aplicados a Homero.

Felizmente, nem Rosa nem Homero são exclusivamente matéria escrita; a passagem do material poético sonoro de seus textos extrapola o mundo estável, permanente e indefinidamente recuperável. É nesse sentido que buscamos detectar ruídos sonoros em ambos e comprovar que a contaminação entre formas de expressão - tanto na produção quanto na articulação e interpretação de mensagens veiculadas - pode multiplicar os potenciais semânticos a enriquecer a obra.

Investigar a possibilidade de ocorrência de metaplasmos factíveis (por adição, supressão, transposição de fonemas e transformação dos mesmos) através do exercício de mudanças de forma (alterações fonéticas) no léxico homérico e rosiano com vistas à hermenêutica literária é, a partir de agora, nosso objetivo. Postulamos o discurso oral como uma zona de resistência e de provocação poética implícita entre gregos e "catrumanos".

No ensaio "Rapsodo do sertão: da lexicogênese à mitopoese", Walnice Nogueira Galvão, sem qualquer pretensão filológica, intuiu sabiamente muitas marcas gregas no nome do narrador de Grande Sertão: veredas. Além de Galvão, a poeta e tradutora Dora Ferreira da Silva apontou uma hermenêutica extraordinária a respeito do papel de Rosa no nosso sistema literário; ela o interpretou como "o bardo do Brasil, inventor de mundos, a nossa paideia, o nosso Homero”. Sem dúvida, paideia é o que fizeram os gregos a partir de Homero; ele os constituiu como nação literária, deu-lhes uma língua comum e uma cultura de prestígio. Da terminologia de Librandi, que, por seu turno, retoma as ponderações de Jean Luc-Nancy e de Derrida, tomamos a expressão "escrita aural" (minimizamos por instantes a leitura "visual") e investigamos a verdade inconclusa das palavras.

Observamos que há, verdadeiramente, inúmeras possibilidades poéticas nos metaplasmos. A que primeiro salta aos olhos no Grande Sertão: veredas é o rotacismo, agregando-se a ele o lambdacismo comum em regiões do interior de Minas Gerais. Lido sob o signo do rotacismo, o nome Riobaldo, "pelo ouvido", é, nada mais, nada menos que um Rio Bardo, um "Rio Cantador". O habitante de Sete Lagoas, Paraopeba, Andrequicé, Várzea da Palma, Cordisburgo e imediações ainda pronuncia Riobaldo, por exemplo, como se escrevêssemos "Riobardo". Trata-se de dizer o 'l' que antecede uma dental ('t' ou 'd') como um ' $r$ ' (às vezes isso ocorre igualmente como um ' $u$ '). 
O fenômeno fonético que comentamos é um entre inúmeros e se dá como amplificador de sentido na obra magna de Rosa. Diplomata e poliglota, o escritor desconstrói o preconceito linguístico para criar, através dele, alta literatura, integrando brasileiros e resgatando eruditismos primevos. Sobre isso, recordamos o valioso trabalho de Marcos Bagno acerca do preconceito linguístico. ${ }^{13}$

Assim procede Guimarães Rosa: projeta o jogo de um metaplasmo na denominação do protagonista do romance. O nome poderia ser interpretado como um composto do substantivo "rio" com o adjetivo "baldo". Pronunciado levando em conta a possibilidade do rotacismo, passa a soar como "rio bardo", termo formado por dois substantivos, "rio" e "bardo". Esse último tem função adjetiva, levando-nos a "rio cantante", "rio cantador" ou, ainda, "rio aedo", que aqui se propõe em referência ao aedo por excelência dos gregos. De fato, a palavra RiobaRdo carrega um significado ancestral que poderá ser perdido sem prejuízo do nome, mas que, resgatado, fecunda-nos.

Poderíamos elencar mais exemplos; o processo é interessante. Contudo, abraçando a hipótese de que Rosa aplica o estratagema em várias passagens, citamos mais uma: "Dor do corpo e dor da ideia ${ }^{14}$ marcam forte, tão forte como o todo amor e raiva de ódio. Vai, mar...”. Nesse trecho, pode-se ler simultaneamente, na palavra "mar", um substantivo e o advérbio "mal", numa polissemia acrescida pelo lambdacismo (fenômeno inverso ao rotacismo). Outras passagens, todas repletas de sentidos acumulados, deixamo-las (sem esgotá-las) ao pé da página, ${ }^{15}$ mas passamos a um propício, último e rápido exemplo de metaplasmo rosiano

\footnotetext{
13 “ $\mathrm{Na}$ visão preconceituosa dos fenômenos da língua, a transformação de $\mathrm{L}$ em $\mathrm{R}$ nos encontros consonantais como em Cráudia, chicrete, praca, broco, pranta é tremendamente estigmatizada e às vezes é considerada um 'atraso mental' das pessoas que falam assim. Ora, estudando cientificamente a questão, é fácil descobrir que não estamos diante de um traço de 'atraso mental' dos falantes 'ignorantes' do português, mas simplesmente de um fenômeno fonético que contribuiu para a formação da própria língua portuguesa. (...) Se fôssemos pensar que as pessoas que dizem Cráudia, chicrete, praca, broco, pranta têm algum 'defeito' ou 'atraso mental', seríamos forçados a admitir que toda a população da província romana da Lusitânia também tinha esse mesmo problema na época em que a língua portuguesa estava se formando. E que o grande Luís de Camões também sofria desse mesmo mal, já que ele escreveu ingrês, pubricar, pranta, frauta, frecha na obra que é considerada até hoje o maior monumento literário do português clássico, o poema Os Lusíadas." (Bagno, 2002, p. 40-41).

${ }^{14}$ Se praticarmos o metaplasmo da aglutinação, 'junção indevida', para dor de ideia, lemos: dor doida... dor doída... doido...

15 "Estão aí, de armas/almas areiadas/arreadas/areadas. A metade dos nossos, que se apeavam, no avanço, entremeados disfarçantes, suas armas/almas em arte - escamoteados pelas árvores - e de repente ligeiros se jazendo: para o rastejo; com as cabeças, farejavam; toda a vida! Aqueles sabiam brigar, desde de nascença? Só avistei isso um instante. Era certo. Deus em armas/almas nos guardava. Catrumanos dos gerais. Pobres, mas atravessados de armas/almas, e com cheias cartucheiras." Veja-se também aqui o jogo armas/almas, ecoado por palmas e parmas: "Eu estava sozinho, num repartimento dum rancho, eu estava deitado numa esteira de taquara. Ao perto de mim, minhas armas/almas. $\mathrm{O}$ rancho era na borda-da-mata. De tarde, como estava sendo, esfriava um pouco, por pejo de vento - o que vem da Serra do Espinhaço - um vento com todas as almas/armas. Arrepio que fuxicava
} 
de aglutinação: “... Não devia de ter querido contra Joca Ramiro dar combate, não devia-de. Não. Confesso culpa nem retrauta, porque minha regra é: tudo que fiz, valeu por bem feito. É meu consueto. Mas, hoje, sei: não deviade." (Rosa, GSV, 2009, p. 182).

Trata-se de sucessivas ocorrências do recurso de "junção indevida" (a primeira foi comentada na nota 10, socolor): deviade, ou seja, "devia de"; podemos realçar igualmente a palavra retrauta por "retreta" (retraite/francês - retirada) e, ademais, o vocábulo consueto, arcaísmo elegante. Devemos crer, contra a voz do narrador, que o que não falta nessas linhas diversas é disfarce...

O uso de metaplasmo em Homero é comum. Paralelos com a junção indevida de Rosa são factíveis. Podemos recordar, inclusive, um comentário de escoliasta para o verso 6 do

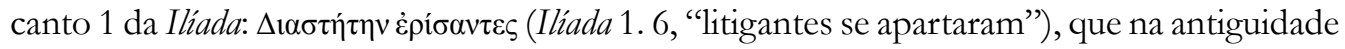

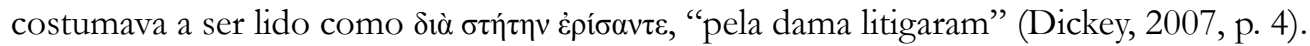

Utilizando o recurso dos antigos, propomos um jogo com o verso 1 do canto 1 ,

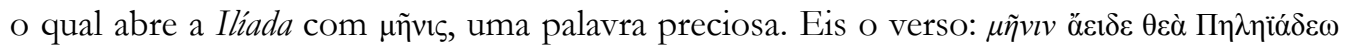
A $\chi \imath \lambda$ ños.../ Canta-me a cólera - ó deusa - funesta de Aquiles Pelida... (em tradução de Carlos Alberto Nunes). Essa palavra $\mu \tilde{n} v ı \varsigma$ é bastante estudada. ${ }^{16}$ Sentimento de deuses, ela, naturalmente, eleva o herói Aquiles; fá-lo divino e digno de temor. O termo é, nesse caso,

as folhagens ali, e ia, lá adiante longe, na baixada do rio, balançar esfiapado o pendão branco das canabravas. Por lá, nas beiras, cantava era o joão-pobre [Serpophaga nigricans], pardo [bardo/valdo], banhador. Me deu saudade de algum buritizal. Saudades, dessas que respondem ao vento; saudade dos Gerais. O senhor vê: o remôo do vento nas palmas/parmas dos buritis todos, quando é ameaço de tempestade. Alguém esquece isso? O vento é verde. Aí, no intervalo, o senhor pega o silêncio põe no colo." (Rosa, GSV, 2009, p. 188).

${ }^{16}$ A história destaca a palavra $\mu$ ĩvı. Segundo Miller ela é usada "only of gods and heroes (Muellner, 1996, p. 127), mostly Achilles (four times out of twelve). In the Odyssey $\mu$ ĩvis occurs four times, in Hesiod one time, and the Hymns two times, always of a god. Mĩvıs thus elevates Achilles to the divine sphere (Watkins, 1977). The other characters fear the wrath of Achilles, as they fear the wrath of a

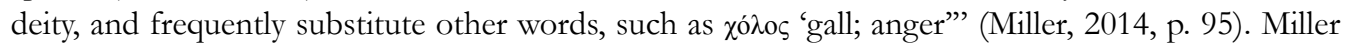
continua: "For Muellner (1996, p. 194) $\mu$ ĩvıs is 'the sacred name of the ultimate sanction against tabu behavior.' Moreover, $\mu$ ĩvı is not merely the wrath of a deity, as towards a mortal, since it is never used

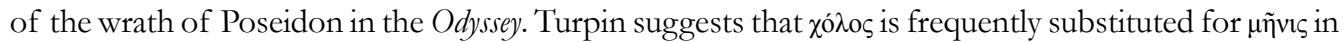
bk. 9 to trivialize Achilles' obstacle in overcoming it by suggesting that it really is something internal after all, over which he has control. But as emphasized by Redfield (1994), the sudden departure of Achilles' anger at $16.60 \mathrm{ff}$ - the very next day after his rejection of the embassy - supports the idea that his anger was not subject to reason. Redfield (1979, p. 101) also notes that $\mu$ ñvı is personified, for otherwise only gods, curses (Odyssey only), and Achilles (22.422) inflict ä $\lambda \gamma \varepsilon \alpha$ 'pains'. Significantly,

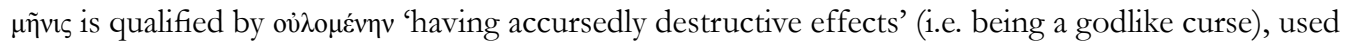
mostly of persons or to personify things, such as Circe's drugs (x.394) and Achilles' armor won

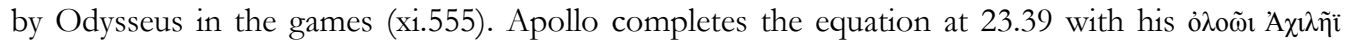
'destructive Achilles'. The destructive $\mu$ ĩvı that triggers the action of the Iliad is annularly framed by غ̇píavic (1.6) 'the two (stood apart) contending in strife' (van Otterlo, 1948, p. 66; Stanley, 1993, p. 326).” (Miller, 2014, p. 97). 


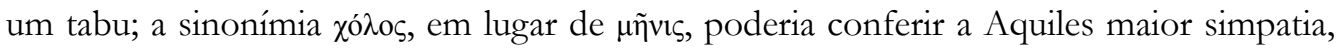
fazê-lo mais humano e próximo.

Para nosso exercício de amplificação através de hipóteses de metaplasmo, vamos aplicar à $\mu$ ñvı uma possibilidade de hipértese. ${ }^{17}$ Acreditamos ser possível, com o abono de Pierre Chantraine, ${ }^{18}$ que atesta as metáteses de quantidade em Homero; de Herbert Smyth, ${ }^{19}$ que indica a variação no ático, bem como a transferência de quantidade (hipértese) no épico; e, finalmente, Liddell-Scott, ${ }^{20}$ que registra possíveis variações de quantidade e timbre interessantes para nosso escopo.

Projetando as situações arroladas para uma hipotética performance de Homero realizada por um cidadão ático, em Atenas, seria razoável pensar a seguinte hipértese: $\mu$ ñvıs por $\mu \check{\alpha} v i \alpha$, com intercâmbio de quantidade e deslocamento interno de um fonema, de uma sílaba para outra sílaba, fenômeno bastante conhecido no grego (Allen, 1871, p. 19), além de - se levarmos em conta o fluxo contínuo da enunciação do verso 1 da Ilíada ( $\mu$ ñvı ó $\varepsilon ı \varepsilon$ $\theta \varepsilon \grave{\alpha})$ com ligadura entre as palavras.

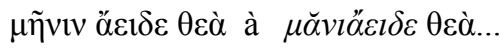

O campo semântico - na leitura oral pensada com o metaplasmo se alarga; "ira", $\mu \tilde{\eta} v ı v$, se muda em "loucura", "desvario" e "sanha", o que possibilita, em interpretação acumulativa, um potencial enorme para o poema como um todo. De fato, todos sabem, quando Aquiles dá largas a sua ira-divina/loucura-apaixonada/sanha-insensata/áscua-viva, o poema ganha em magnitude. Áscua do Aquiles Peleu: harpeja deusa!

\footnotetext{
${ }^{17}$ Do tipo [pobrema] por [problema]; [cardaço] por [cadarço].

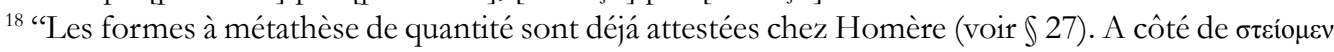

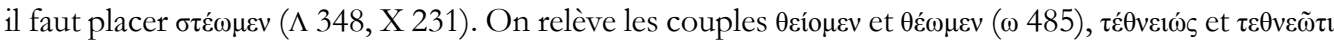

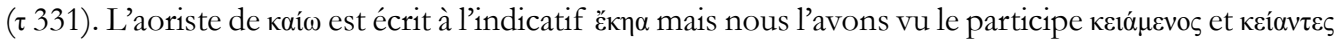

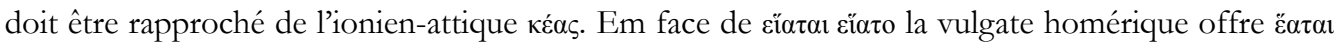

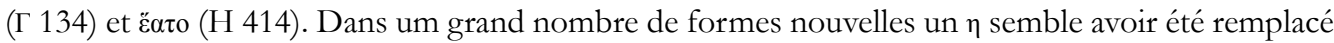
para la fausse diphtongue -El-. Lorsque cette graphie est attestée on trouve généralement en ionien-

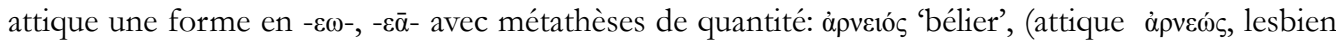

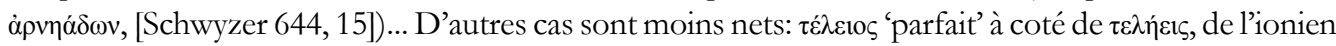

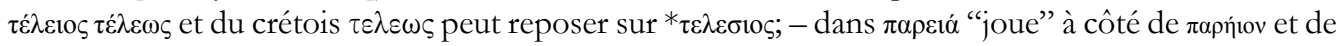

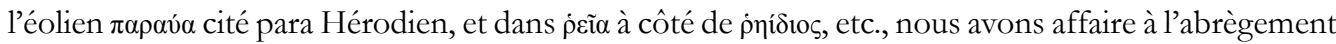
d'une diphtongue en $\eta$ mais $\dot{\rho} \varepsilon \tilde{\alpha} \alpha$ peut aussi recouvrir $\dot{\rho} \tilde{\eta} \alpha$, cf. dorien $\dot{\rho} \bar{\alpha}$." (Chantraine, 1948, p. 9-10). 19 “30. Attic $\boldsymbol{\eta}, \overline{\boldsymbol{\alpha}}-$ Attic has $\eta$ for original $\bar{\alpha}$ of the earlier period as $\varphi \eta \mu \eta$ report (Lat. fäma). Ionic also has $\eta$ for original $\bar{\alpha}$. Doric and Aeolic retain original $\bar{\alpha}(\varphi \alpha \mu \bar{\alpha})$." E ainda, "32. In the choruses of tragedy

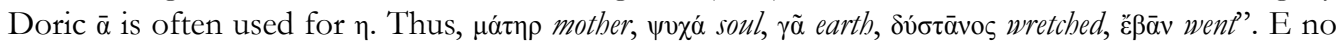

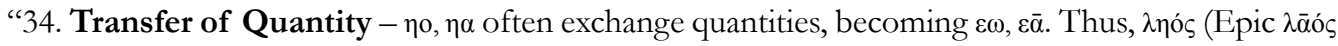

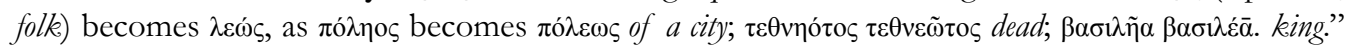
(Smyth, 1920, p. 14ss).

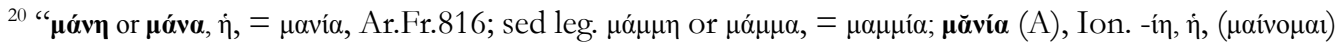

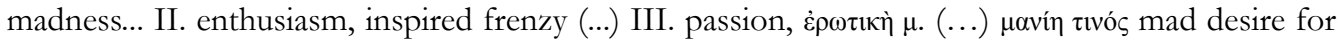

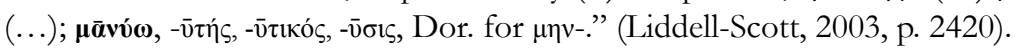




\section{Apocopando}

Abortemos os muitos exemplos. Não temos páginas para tantos. Cheguemos a termo. Viu-se que, seja em Homero, seja em Rosa, a ausculta de possíveis alterações fonéticas em termos recorrentes e particulares na obra escrita amplia sua reverberação poética e mostra a riqueza que a variação linguística, no interior de uma língua, pode alargar enormemente o escopo de uma obra. São inúmeras as possibilidades de abordagem oral que se abrem para o entendimento mais aprofundado desses corpora. Esperamos com isso promover um trabalho acadêmico mais politicamente democrático; quebrar as correntes do preconceito linguístico; flexibilizar a escritura; projetar a literatura rosiana nos estudos clássicos e iluminar e revivificar Homero.

\section{REFERÊNCIAS}

ABDALA Jr., Benjamin. Literatura comparada e relações comunitárias, hoje. São Paulo: Ateliê Editorial, 2012.

AGAMBEN, Giorgio. O que é contemporâneo? e outros ensaios. Tradução: Vinícius Nicastro Honesko. Chapecó: Argos, 2009.

ALLEN, Frederic De Forest. On the so-called Attic Second Declension. Transactions of the American Philological Association (1869-1896), v. 2, p. 18-34, 1871.

ARRIGUCCI, Davi. O mundo misturado. Romance e experiência em Guimarães Rosa. Novos Estudos Cebrap, n. 40, p. 7-29, 1994.

BAAH, Robert. Miguel de Unamuno and the Art of Apocopation. Revista Hispánica Moderna, año 56, n. 1, p. 17-27, 2003.

BAGNO, Marcos. Preconceito linguístico: o que é, como se faz. São Paulo: Loyola, 2002.

BAGNO, Marcos. Gramática Pedagógica do Português Brasileiro. São Paulo: Parábola Editorial, 2012.

BIZONI, Alessandra Moura. A cicatriz do Tatarana: o sagrado feminino em Grande Sertão: veredas. Dissertação (Mestrado em Teoria da Literatura e Literatura Comparada) - Programa de Pós-Graduação em Letras, Universidade do Estado do Rio de Janeiro, Rio de Janeiro, 2013.

BIZZARRI, Edoardo; ROSA, João Guimarães. Guimarães Rosa: correspondência com seu tradutor italiano Edoardo Bizzarri. São Paulo: T. A Queiroz; Instituto Cultural Ítalo-Brasileiro, 1980.

BOLLE, Willi. Grandesertão.br: o romance de formação do Brasil. São Paulo: Duas Cidades/ Editora 34, 2004.

BOLLE, Willi. Representação do povo e invenção de linguagem em Grande Sertão: veredas. Scripta, Belo Horizonte, v. 5, n. 10, p. 352-66, 2002.

CAMPOS, Haroldo de. Entrevista. 2003. Disponível em:

https://www.youtube.com/watch?v=tVTSZbWiyZA. Acesso em: 20 out. 2015. 
CANDIDO, Antonio. O sertão e o mundo. DLÁLOGO. Revista de Cultura, São Paulo, n. 8, p. 5-18, nov. 1957. Número especial sobre Guimarães Rosa.

CANDIDO, Antonio. No Grande Sertão. In: Textos de intervenção. Seleção, apresentação e notas de Vinícius Dantas. São Paulo: Duas cidades/Editora 34, 2002. p. 190-92. CARVALHO, David. William Myron Davis vasculha o Grande sertão: veredas. Suplemento Literário, p. 10, 27 nov. 1976. Disponível em:

http:/ /www.letras.ufmg.br/websuplit/arquivos.php?a=1976\&c=11053111197610. Acesso em: 10 fev. 2019.

CASTRO, Nei Leandro de. Universo e vocabulário do grande sertão. Rio de Janeiro: Achiamé, 1982.

CEZAR, Adelaide Caramuru; SANTOS, Volnei Edson. O insólito provocado pelo encontro dos jagunços com os catrumanos em Grande Sertão: veredas, de João Guimarães Rosa. In: CONGRESSO LUSO BRSILEIRO DE CIÊNCIAS SOCIAIS: (DES)IGUALDADES, XI., 2011, Salvador. Anais [...]. Salvador: Universidade Federal da Bahia, 2011.

CHANTRAINE, Pierre. Grammaire homérique. Phonétique et Morphologie. Paris: Klincksieck, 1948. t. 1.

CUNHA, Antônio Geraldo. Dicionário Histórico das Palavras Portuguesas de Origem Tupi. São Paulo; Brasília: Companhia Melhoramentos; UnB, 1978.

CUNHA, Euclides da. Os Sertões. São Paulo: Três, 1984. Disponível em: http://www.bibvirt. futuro.usp.br. Acesso em: 10 out. 2017.

CUNHA, José Carlos Chaves da; RIVENE, Paul. Para o estudo do vocabulário das interações orais: propostas metodológicas. Belém: EDUPA, 2003.

DUBATTI, Jorge. Teatro-Matriz y Teatro Liminal: la liminalidad constitutiva del acontecimiento teatral. Cena, n. 19, p. 1-17, 2016.

DUFOUR, Médéric. Traité élémentaire des synonymes Grecs. Paris: Librairie Armand Colin, 1910. EDMUNDS, Lowell. Intertextuality and the reading of Roman poetry. Baltimore; Maryland: The John Hopkins University Press, 2001.

FOLEY, John Miles. "Reading" Homer through oral tradition. College Literature, v. 34, n. 2, p. 1-28, 2007.

GALVÃO, Walnice Nogueira. Rapsodo do sertão: da lexicogênese à mitopoese. Cadernos de Literatura Brasileira, n. 20-21, p. 144-86, 2006. Disponível em: https://issuu.com/ims_ instituto_moreira_salles/docs/clb_guimar_es_rosa.

HAZIN, Elizabeth. De Aquiles a Riobaldo: ação lendária no espaço mágico. Revista da Anpoll, n. 24, v. 1, p. 291-303, 2001. doi: https://doi.org/10.18309/anp.v1i24.29.

HINDS, Stephen. Allusion and intertext: dynamics of appropriation in Roman poetry. Cambridge: Cambridge University Press, 1998. 
HOMER. Odyssey of Homer. Introd. e comm. W. B. Stanford. London: St Martin Press, 1987. v. 1.

HOMERI Opera Iliadis. Oxford: Oxford University Press, 1989. 2 t.

HOMERO. Iliada. Trad. de Carlos Alberto Nunes. São Paulo: Edições de ouro, s/d.

HOMERO. Iliada. Trad. de Frederico Lourenço. Lisboa: Edições Cotovia, 2005.

HOMERO. Odisseia. Trad. de Frederico Lourenço. Lisboa: Edições Cotovia, 2003.

HOMERO. Odisseia. Trad. de Carlos Alberto Nunes. Rio de Janeiro: Ediouro, 2000.

HOMERO. Odisseia. Trad. de Christian Werner. São Paulo: Cosac Naify, 2014.

HOUAISS, Antônio; VILLAR, Mauro. Dicionário Houaiss da língua portuguesa. Rio de Janeiro: Objetiva, 2009.

LALLOT, Jean. L'invention du nom propre dans la tradition grecque ancienne. In: Études sur la grammaire alexandrine. Paris: Vrin, 2012. p. 328-40.

LATORRE, Vanice Ribeiro Dias. Uma abordagem etnoterminológica de Grande Sertão: veredas. Dissertação (Mestrado) - Programa de Pós-Graduação em Semiótica e Linguística Geral, Universidade de São Paulo, São Paulo, 2011.

LEDERER, Richard. A light-hearted look at Greek figures of rhetoric. Word Ways, v. 46, n. 1, p. 57-64, 2013. Disponível em: http://digitalcommons.butler.edu/cgi/viewcontent.cgi?a rticle $=5210 \&$ context $=$ wordways. Acesso em: 19 out. 2016.

LEONEL, Maria Célia de Moraes; VASCONCELOS, Sandra Guardini Teixeira. Arquivo Guimarães Rosa. Revista do IBE, n. 24 p. 177-80, 1982.

LIBRANDI-ROCHA, Marília. Grande sertão: veredas e a defesa do ficcional. Luso-Brazilian Review, v. 52, n. 1, p. 95-109, 2015.

LIBRANDI-ROCHA, Marília. A literatura em trânsito ou o Brasil é dentro da gente (contração, expansão e dispersão). In: MONTEIRO, Pedro Meira (Org.). A primeira aula: trânsitos da literatura brasileira no estrangeiro. São Paulo: Itaú Cultural, 2014. p. 31-37.

LIDDELL, Henry Georg; SCOTT, Robert. A Greek-English Lexicon. Oxford: Clarendon Press, 2003.

LÓPEZ FOLGADO, Vicente. La sangre del espíritu: ideas de Unamuno sobre la lengua y la traducción. El Liberal, Madrid, p. 65-72, 1923. Disponível em: https://cvc.cervantes.es/ lengua/iulmyt/pdf/traduccion_98/08_lopez.pdf. Acesso em: 15 jul. 2018.

LORENZ, Günter; ROSA, João Guimarães. Diálogo com Guimarães Rosa (Congresso de Escritores Latino-Americanos, Gênova, janeiro de 1965). In: ROSA, João Guimarães. Fiçcão completa. Rio de Janeiro: Nova Aguilar, 2009. v. 1, p. 31-65.

MALHADAS, Daisi; DEZOTTI Maria Celeste Consolin; NEVES, Maria Helena de Moura. Dicionário Grego-Português (DGP). Cotia: Ateliê Editorial, 2006-2010. 5 v. 
MANUELZÃO e Bananeira (parte 3). Direção: Geraldo Elísio. Roteiro e produção: Geraldo Elísio; A. B. Silvestre. Belo Horizonte, 2003. Disponível em: https://www.youtube.com/ watch?v=Gm11_9tuZqo. Acesso em: 14 out. 2017.

MARÇOLLA, Bernardo A. Ritmo em Grande Sertão: Veredas. Revista da Anpoll, v. 1, n. 24, p. 229-259, 2008. doi: https://doi.org/10.18309/anp.v1i24.27

MARTINS, Wilson. "Mire e veja": a teoria sartreana do olhar utilizada na explicação do drama central de Grande sertão. Jornal do Brasil, Rio de Janeiro, p. 11, 17 maio 1980.

MARTINS COSTA, Ana Luiza. Rosa ledor de Homero. Revista USP, v. 36, p. 46-73, 1997-1998.

MARTINS COSTA, Ana Luiza. João Guimarães Rosa: viator. Tese (Doutorado)-Programa de Pós-Graduação em Letras, Instituto de Letras, Centro de Educação e Humanidades, Universidade do Estado do Rio de Janeiro, Rio de Janeiro, 2002.

MARTINS COSTA, Ana Luiza. Veredas de Viator. Cadernos de Literatura Brasileira, n. 20-21, p. 10-58, 2006. Disponível em: https://blogdoims.com.br/cadernos-de-literatura-brasileiradisponiveis-online/\#João-Guimarães-Rosa.

MARTINS COSTA, Ana Luiza. Via e viagens: a elaboração de Corpo de baile e Grande sertão: veredas. Cadernos de Literatura Brasileira, n. 20-21, p. 187-235, 2006. Disponível em: https:// blogdoims.com.br/cadernos-de-literatura-brasileira-disponiveis-online/\#João-GuimarãesRosa

MEYER-CLASON, Hans Curt; ROSA, João Guimarães. João Guimarães Rosa: correspondencia com seu tradutor alemão Curt Meyer-Clason (1958-1967). Organização de Maria Aparecida F. M. Bussolotti e tradução de Erlon José Paschoal. Rio de Janeiro: Nova Fonteira; Academia Brasileira de Letras; Editora UFMG, 2003.

MILLER, D. Gary. Ancient Greek Dialects and Early Authors: Introduction to the Dialect Mixture in Homer, with notes on lyric and Herodotus. Berlin: Walter de Gruyter, 2014.

MINCHIN, Elizabeth. Memory and Memories: Personal, Social, and Cultural Memory in the Poems of Homer. In: MONTANARI, Franco; RENGAKOS, Antonios; TSAGALIS, Christos (Ed.). Homeric Contexts Neoanalysis and the Interpretation of Oral Poetry. Berlin: Walter de Gruyter, 2012.

MINER, Earl. Poética Comparada. Tradução de Angela Gasperin. Brasília: Ed.UnB, 1996.

MONTANARI, Franco; RENGAKOS, Antonios; TSAGALIS Christos (Ed.). Homeric Contexts Neoanalysis and the Interpretation of Oral Poetry. Berlin: Walter de Gruyter, 2012.

MONTEIRO, Carlos Augusto de Figueiredo. O espaço iluminado no tempo volteador (Grande sertão: veredas). Estudos Avançados, v. 20, n. 58, p. 47-64, 2006.

MUNANGA, Kabengele. Aula ministrada no Programa de Educação sobre o Negro na Sociedade Brasileira (PENESB), Núcleo de Estudos Afros da Universidade Federal Fluminense. Niterói: UFF, 2009/2010. Disponível em: https://www.youtube.com/ watch?v=7FxJOLf6HCA. 
NAGY, Gregory. Genre and Occasion. Mètis. Anthropologie des Mondes Grecs Anciens, v. 9-10, p. 11-25, 1994. doi: https://doi.org/10.3406/metis.1994.1008. Acesso em: 9 fev. 2019.

OLIVEIRA, Luís Cláudio Vieira de. Ave, palavra. Caligrama: Revista de Estudos Românicos, v. 13, p. 139-53, 2008. doi: http://dx.doi.org/10.17851/2238-3824.13.0.139-153

PARRY, Milman. The making of homeric verse (Adam Parry ed.). Oxford: Clarendon Press, 1971.

PINTO, Manuel da Costa. Guimarães Rosa por ele mesmo: o escritor no meio do redemunho. Cadernos de Literatura Brasileira, n. 20-21, p. 77-93, 2006. Disponível em: https://blogdoims. com.br/cadernos-de-literatura-brasileira-disponiveis-online/\#João-Guimarães-Rosa

PINTO, Manuel da Costa. O império do Belo Monte: vida e morte de Canudos. São Paulo: Fundação Perseu Abramo, 2001.

QUINTILIAN. Institutio Oratoria, Books I-III. Translation by H. E. Butler. Cambridge, MA: Harvard University Press, 1996.

REECE, Steve. Homer's Winged Words The Evolution of Early Greek Epic Diction in the Light of Oral Theory. Leiden: Brill, 2009.

RÓNAI, Paulo. Os vastos espaços. In: ROSA, João Guimarães. Primeiras Histórias. Rio de Janeiro: Nova Fronteira, 2001, [s/p].

ROSA, João Guimarães. Fição Completa. Organização de Eduardo F. Coutinho. Rio de Janeiro: Nova Aguilar, 2009. v. 1 e 2.

ROSA, João Guimarães. Grande Sertão: Veredas. In: . Fiç̧ão Completa. Organização de Eduardo F. Coutinho. Rio de Janeiro: Nova Aguilar, 2009. v. 2, p. 7-395.

ROSA, João Guimarães. Grande sertão: veredas. 11. ed. Rio de Janeiro: José Olympio, 1976.

ROSA, João Guimarães. O espelho. In: . Fiç̧ão Completa. Organização de Eduardo F. Coutinho. Rio de Janeiro: Nova Aguilar, 2009. v. 2, p. 446-64.

ROSA, João Guimarães. Entrevista com Walter Friedrich Höllerer. Disponível em: https:/ /ufmg. $\mathrm{br} /$ comunicacao/noticias/faculdade-de-letras-promove-seminario-em-cordisburgo-sobretraducoes-de-guimaraes-rosa. Acesso em: 2 dez. 2017. A mesma entrevista pode ser vista em: https://www.youtube.com/watch?v=ndsNFE6SP68.

SCHAFER, Raymond Murray. Quando as palavras cantam. In: O ouvido pensante. Tradução Marisa Trench de O. Fonterrada, Magda R. Gomes da Silva, Maria Lúcia Pascoal. São Paulo: UNESP, 1991, p. 207-67.

SCODEL, Ruth. Homeric signs and flashbulb memory. In: WORTHINGTON, Ian; FOLEY, John Miles (Ed.). Epea and Grammata: Oral and written communication in ancient Greece. Leiden: Brill, 2002. p. 99-116.

SILVA, Dora Ferreira da. Às margens de Rosa. Cadernos de Literatura Brasileira, n. 20-21, p. 59-60, 2006. Disponível: https://blogdoims.com.br/cadernos-de-literatura-brasileiradisponiveis-online/\#João-Guimarães-Rosa. 
SMYTH, Herbert. Greek Grammar. New York: American Book Company, 1920.

SOUZA, Marisa Giannecchini Gonçalves de. Olhos de ver, olhos de enganar. Itinerários, n. 0, p. 113-122, 1995.

SPERBER, Susi Frankl. As palavras de chumbo e as palavras aladas. Floema: Caderno de Teoria e História Literária, n. 3, p. 137-157, 2006.

STEINER, George. Depois de Babel, questões de linguagem e tradução. Tradução Carlos Alberto Faraco. Curitiba: UFPR, 2005.

TROGO, Sebastião. A Travessia da Dor no Grande Sertão: Veredas. Travessia, v. 7, n. 15, p. 11-39, 1987.

UM CERTO Manoelzão. Direção: Leonardo Bartucci. Produção: Ronaldo Aguiar. Roteiro: Pedro José F. Nascimento. 1982. 35 mm, 8 min. Disponível em: https://www.youtube.com/ watch?v $=\mathrm{oMQ} 5 \mathrm{uGtvAr} 4 \& \mathrm{t}=2 \mathrm{~s}$. Acesso em: 14 out. 2017.

UTEZA, Francis. Metafísica do Grande Sertão. Tradução José Carlos Garbuglio. São Paulo: USP, 1994.

UNAMUNO, Miguel. El secreto de la vida. jul. 1906. Disponível em: http://www. cervantesvirtual.com/obra-visor/el-secreto-de-la-vida-776727/html/4933c36d-bdae-40919d98-e6d5232308f7_2.html. Acesso em: 30 jul. 2018.

VERLANGIERI, Iná Valéria Rodrigues. J. GUIMAR ÃES ROSA - correspondência inédita com a tradutora norte-americana Harriet de Onis (Parte I). Dissertação (Mestrado) - Programa de PósGraduação em Letras, Estudos Literários da Faculdade de Ciências e Letras, Universidade Estadual Paulista, Araraquara, 1993.

VESSELLA, Carlo. Sophisticated speakers. Atticistic pronunciation in the Atticist lexica. Berlin: De Gruyter, 2018.

WERNER, Christian. Afamada estória: Famigerado (Primeiras Estórias) e o canto IX da Odisseia. Nuntius Antiquus, v. 8, p. 29-50, 2012. doi: http://dx.doi.org/10.17851/1983-3636.8.1.29-50

WISNIK, José Miguel. O recado do morro [João Guimarães Rosa]. Grandes cursos de Cultura na TV. Disponível em: https://www.youtube.com/watch?v=ePXz1 rhGWCM.

WORTHINGTON, Ian; FOLEY, John Miles (Ed.). Epea and Grammata: Oral and written communication in ancient Greece. Leiden: Brill, 2002.

ZILLY, Berthold. "Procuro chocar e estranhar o leitor". Grande Sertão: Veredas - a poética da criação e da tradução. Fronteiraz, n. 19, p. 4-21, dez. 2017. doi: http://dx.doi. org/10.23925/1983-4373.2017i19p4-31. 